Jurnal komunikasi, ISSN 1907-898X

Volume 9, Nomor 2, April 2015

\title{
Mythology Politik Jawa dalam Pidato Anas Urbaningrum \\ (Analisis Semiotika Roland Barthes dalam Pidato Anas Urbaningrum Terkait Kasus Korupsi Hambalang)
}

\author{
Hani Yuniani \\ Mahasiswa Program Studi Ilmu Komunikasi Universitas Mercu Buana Angkatan XIV
}

\begin{abstract}
Anas Urbaningrum received attention from the media lately because of his messages consisting multi-interpretation statements through the analogy of puppet story. Anas' speech, which is driven on semiotics review, becomes an interesting topic for a research due to its connection with national politics reality and dynamic within this political year. The result of this research shows that Anas's message indicated Susilo Bambang Yudhoyono as the narrator/director of Hambalang case series. The Hambalang Project gratification case is a project prepared by SBY in order to overthrow Anas as the Chairman of Partai Demokrat that was legally gained. KPK becomes SBY's assistant to smoothen the operation and to prepare the plot. Demokrat Party still has no democratic tradition because of the strong feeling of aristocracy in the party's internal body.
\end{abstract}

Keywords: Hambalang case, Political Speech, Semiotics

\section{Pendahuluan}

Pernyataan politik dari seorang politisi sekelas Anas Urbaningrum menarik untuk menjadi bahan perbincangan dan kajian dalam komunikasi politik dan media. Gaya bicara Anas Urbaningrum yang santun, tegas, dan pembawaannya yang tenang, dinilai sebagian pengamat sebagai pribadi yang cerdas dan matang. Namun, setelah menampilkan diri sebagai sosok yang santun, banyak mengalah, dan mengikuti kemauan SBY, belakangan AU sering melontarkan kalimat-kalimat dan istilah yang menyerang lawan politiknya,terutama setelah namanya disebut-disebut terlibat dalam kasus gratiikasi proyek Hambalang. walaupun masih samar, dengan simbol dan kodekode yang menggelitik untuk menelusurinya lebih dalam. Tidak saja di media massa, Anas kerap memunculkan statement di facebook, dan kicuan di twitter, serta status update-nya di BBM (Blacberry Messanger). Namun dalam penelitian ini, objek penelitian hanya megambil dua pidato Anas ketika mengundurkan diri dari Ketua Umum Partai Demokrat yang disampaikan di kantor DPP Partai Demokrat dan saat dirinya ditahan KPK pada 14 Januari 2014.

Anas sempat menuliskan status atau personal message "Politik Para Sengkuni" dalam BlackBerry-nya setelah muncul pengumuman hasil survei Saiful Mujani Research and Consuliing (SiviRC). Survei SMRC itu menempatkan Demokrat di posisi ketiga parpol yang dipilih responden jika pemilu diadakan saat ini. Dalam survei itu, Demokrat meraih perolehan 8,3 persen suara.(Kompas.com, 3 Februari 2014) 
Kesemuanya merupakan pengejawentahan pemikirannya dalam gelombang tsunami politik yang dialaminya. Anas menampilkan sebuah peristiwa simbolik ketika ia melepas jaket berwarna biru dalam peristiwa pengunduran dirinya dari jabatan Ketua umum Partai Demokrat. Ekspektasi masyarakat yang demikian tingginya kepada upaya-upaya pemberantasan korupsi membuat masyarakat mengidam-idamkan munculnya sang wistle blower yang berani mengungkap praktik-praktik korupsi yang terjadi di dalam pemerintahan. Anas sebagai politisi yang dekat dengan lingkaran kekuasaan dianggap tahu banyak akan pengaturan berbagui macam proyek yang merugikan negara puluhan hingga ratusan milyar. Kemunculan sang wistle blower memberi harapan sekaligus mejadi santapan empuk lawan-lawan politik dalam partai Demokrat maupun di luar partai. Anas memunculkan pesan-pesan politik sebagai tanda yang sering ditafsirkan media sebagai "perlawanan" terhadap Susilo Bambang Yudhoyono.

Salah satu kunci kesuksesan politisi adalah mampu berkomunikasi, baik terhadap kawan maupun lawan. Dalam istilah politik tak selamanya kawan dijadikan kawan yang sejati, sebaliknya lawan pun dapat dijadikan kawan. Kuncinya adalah bagaimana politisi mengatur keseimbangan berkomunikasi antara kawan dan lawan. Pada saat-saat genting dimana Anas berada dalam posisi terjepit, dia berusaha mengelola kesan di hadapan publik. Anas menyadari, bahwa untuk menghadapi penguasa, diperlukan stategi dan perhitungan yang matang.

Anas Urbaningrum yang lahir dan besar di tanah Jawa sangat memahami bagaimana cara orang Jawa (njawani) mengungkapkan perasaan dan ide, apalagi orang yang berkonfik dengannya pun adalah, orang Jawa, maka komunikasi dengan, gaya tingkat tinggu pun menjadi ciri khas nya. Anas bukan tipikal orang yang hebat bicara, temperamental dan terang benderang dalam kata dan kalimatnya. Pidato politik saat ia mundur dari Ketum Partai Demokrat dan pernyataannya sesaat sebelum masuk ruang tahanan KPK, penuh dengan kode dan tanda yang multitafsir. Ini adalah tugas semiotika dalam mengupas, memaknai dan meghubungkannya dengan realitas politik dan konteks sosio historis yang terjadi pada waktu peristiwa tersebut terjadi.

\section{Analisis Semiotika}

Semiotika pada dasarnya mempelajari kemanusiaan (humanity) memaknai hal (things). Semiotik atau penyelidikan simbol-simbol membentuk tradisi pemikiran yang penting dalam teori komunikasi. Tradisi semiotik terdiri atas sekumpulan teori teori tentang bagaimana tanda-tanda mempresentasikan benda, ide, keadaan, situasi, perasaan, dan kondisi di luar tanda-tanda itu sendiri (Littlejohn, 2009:5 3). Secara etimologis istilah semiotika berasal dan bahasa Yunani "semeion" yang berarti tanda. Semiotika kemudian didefinisikan sebagai studi tentang tanda dan cara tanda-tanda itu bekerja.

Pemikiran Barthes tentang mitos di satu sisi masih melanjutkan pengandaian Saussure tentang hubungan bahasa dan makna atau antara penanda dan petanda. Semiotika yang dibangun Saussure cenderung mengatakan makna sebagai apa yang didenotasikan oleh tanda. Maka tradisi semiotika pada awal kemunculannya cenderung berhenti sebatas pada makna-makna denotatif alias semiotika denotasi. Sementara bagi Barthes, terdapat makna lain yang justru bermain pada level yang lebih mendalam, yakni pada level konotasi. Pada tingkat inilah warisan pemikiran Saussure dikembangkan oleh Barthes dengan 
membongkar praktik pertandaan di tingkat konotasi tanda. Konotasi bagi Barthes justru mendenotasikan sesuatı hal yang ia nyatakan sebagai mitos, dan mitos ini mempunyai konotasi terhadap ideologi tertentu. Skema pemaknaan mitos itu oleh Barthes digambarkan sebagai berikut:

\begin{tabular}{|c|c|}
\hline 1. Penanda & 2. Petanda \\
\hline 3. Tanda & \\
I. PENANDA & I. PETANDA \\
\hline \multicolumn{2}{|c|}{ III. TANDA } \\
\hline
\end{tabular}

Gambar 1. Peta Tanda Roland Barthes Sumber: Roland Barthes (dalam Storey: 1994: 110)

Tanda konotatif tidak hanya memiliki makna tambahan, namun juga mengandung kedua bagian tanda denotatif yang melandasi keberadaannya. Tambahan ini merupakan sumbangan Barthes yang amat berharga atas penyempurnaannya terhadap semiologi Sausure, yang hanya berhenti pada penandaan pada lapis pertama atau pada tataran denotatif semata. Dengan membuka wilayah pemaknaan konotatif ini, 'pembaca' teks dapat memahami penggunaan gaya bahasa kiasan dan metafora yang itu tidak mungkin dapat dilakukan pada level denotatif (Manneke Budiman, dalam Christomy dan Yuwono, 2004: 255). Bagi Barthes, semiotika bertujuan untuk memahami sistem tanda, apapun substansi dan limitnya, sehingga seluruh fenomena sosial yang ada dapat ditafsirkan sebagai 'tanda' alias layak dianggap sebagai sebuah lingkaran linguistik.

\section{Makna Denotasi dan Konotasi}

Roland barthes menggunakan istilah denotasi dan konotasi unuk menunjukkan tingkatan-tingkatan makna. Makna denotasi adalah yang menunjukan arti harfiah atau yang eksplisit dari kata-kata dan suatu fenomena. Makna konotasi merupakan makna tingkatan pertama (primary) yang bersifat objektif yang dapat diberikan terhadap lambanglambang yakni dengan engkaitkan secara langsung antara lambang dengan realitas atau gejala yang ditunjuk. Makna konotasi adalah makna-makna budaya yang terpisah atau berbeda dengan kata dan bentuk-bentuk lain dari komunikasi. (Berger, 1998;13 dalam Barthes; 1994 : 474). 


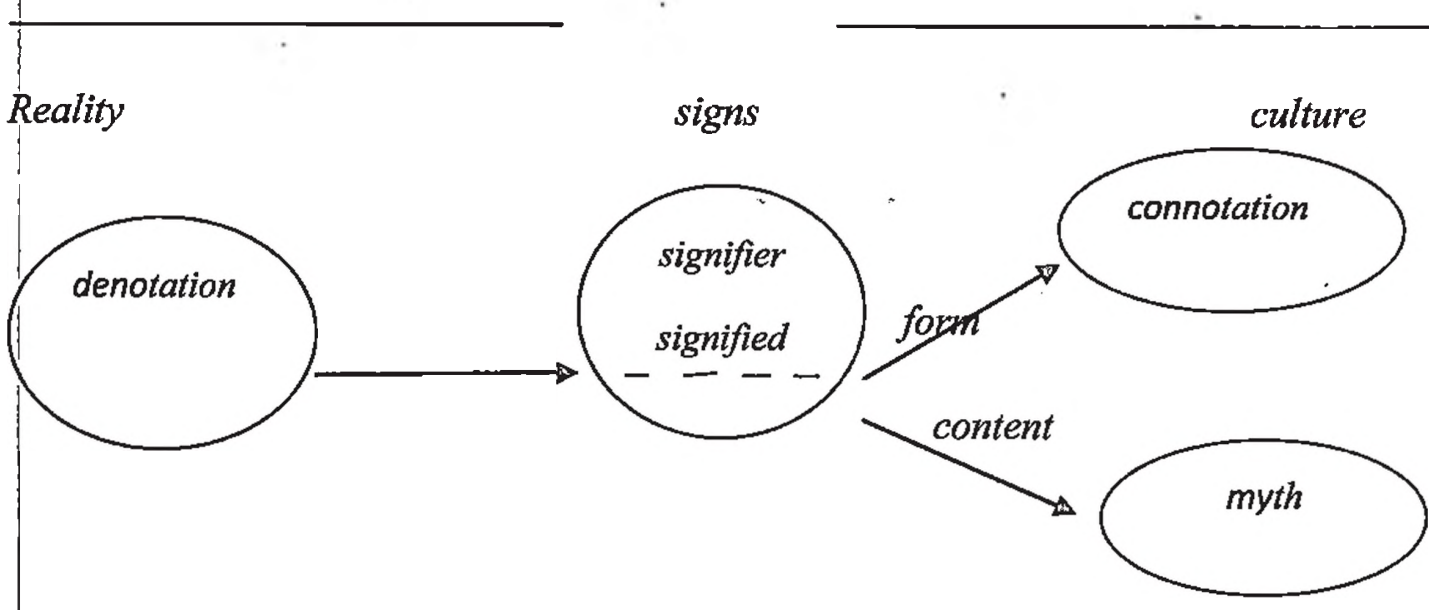

Gambar 2. Model Signifikansi Barthes

Sumber: Fiske, introduction to communication studies, 1990:88

Gambar ini menjelaskan signifikasi tahap pertama merupakan hubungan antara signifier dan signified di dalam sebuah tanda terhadap realitas eksternal. Barthes menyebutnya sebagai denotasi, yaitu makna paling nyata dari tanda. Konotasi adalah istilah yang digunakan oleh barthes untuk enunjukan signifikasi yang kedua. Hal ini menggambarkan interaksi yang terjadi ketika tanda betemu denan perasaan dan emosi dari pembaca serta nilai-nilai dari kebudayaannya. Konotasi mempunya makna subjektif atau intersubjektif. Pemilihan kata-kata kadang meupakan pilihan terhadap konotasi. Dengan kata lain denotasi adalah apa yangg diggambarkan tanda terhadap sebuah objek, sedanggkan konotasi adalah bagaiana caya menggambarkannya. Konotasi bekerja dalam tingkat subjektif, sehingga kehadirannya tidak disadari.

Pada signifikasi yang tahap kedua yang berhubungan dengan isi, tanda bekerja melaui mitos (myth). Mitos adalah bagaimana kebudayaan menjelaskan atau memahami beberap aspek tentan realitas atau gejala alam. Mitos merupakan produk kelas sosial yang sudah mempunyai satu dominasi. Menurut Susilo, (2000, dalam Sobur ; 2001:128) suatu teknik yang menarik dan memberikan hasil yang baik untuk masuk kedalam titik tolak berfikir ideologis adalah mempelajari mitos. Mitos dalam pandangan Susilo adalah suatu wacana dimana suatu ideologi bewujud. Mitos dapat berangkai menjadi mitiologi yang memainkan peranan penting dalam kesatuan budaya.

Kita bisa menemukan ideologi dalam teks dengan jalan meneliti konotasi-konotasi yang terdapa didalamnya (Vanzoezt, 1991:70, dalam Sobur ; 2001:129). Salah satu cara adalah mencari mitologi dalam teks itu. Ideologi adalah sesuatu yang abstrak. Mitologi (kesatuan mitos yang kehoren) menyajikan inkarnasi makna yang mempunyai wadah dalam ideologi. Ideologi harus dapat diceritakan. Cerita itulah mitos.

\section{Pembahasan}

Dilihat dari daerah asalnya, Anas memang memiliki kultur Budaya Jawa yang kental. Ini terlihat dari gaya bicaranya yang santun, hati-hati dan piawai memilih kata dan cermat dalam mengkolaborasi pesan. Sesekali, Anas mengulang kalimatnya, 
dengan tujuan penekanan pada aksen tertentu seperti pada kata "tekanan kekuasaan". Gaya komunikasi Anas sebetulnya, tidak jauh berbeda dari gurunya di Partai Demokrat yaitu Susilo Bambang Yudhoyono. Konteks bahasanya tinggi, Selalu berusaha berkomunikasi dengan bahasa tubuh dan verbal dengan sempurna.Sama halnya dengan tokoh seniornya di Partai Demokrat, Susilo Bambang Yudhoyono, Anas pun jarang tersenyum apalagi tertawa terbahakbahak di hadapan pers. Anas sangat cermat dalam memilih kata, dan memiliki daya ingat yang sangat baik, ia jarang memberikan pidato dengan menggunakan teks.

Anas selama ini dikenal sebagai sosok intelektual ketimbang politisi.
Pembawaannya kalem, bernada datar, dan sangat santun. Barulah ketika ia bergabung dengan Partai Demokrat dan mulai disebut-sebut Nazaruddin terlibat kasus suap proyek Hambalang, maka pernyataan-pernyataannya di televisi mulai sedikit "memanas".

Aspek penting dalam penelitian ini adalah tiga poin utama Barthes (pesan linguistik, pesan ikonik terkodekan, dan pesan ikonik tak terkodekan) dalam mencari mitologi (kesatuan mitos) yang tersirat dalam pidato mundurnya Anas urbaningrum dari Ketua umum Partai Demokrat. Pidato yang berdurasi kurang lebih 15 menit itu mengungkapkan beberapa pesan sebagai berikut :

Tabel 1. Pesan Ikonik Terkodekan

\begin{tabular}{|c|c|c|}
\hline Tanda & Makna Iama & Makna baru \\
\hline $\begin{array}{l}\text { Ekspesi wajah (serius, datar) } \\
\text { Banyak orang memberikan } \\
\text { informasi kepada orang Iain } \\
\text { melalui ekspresi } \\
\text { wajahnya. Wajah yang } \\
\text { berbeda satu sama lain. Anas } \\
\text { Urbaningrum mempunyai } \\
\text { wajah yang kurang ekspresif, } \\
\text { dingin, dan datar. Wajah } \\
\text { seperti ini sebetulnya sulit } \\
\text { dibedakan antara perasaan } \\
\text { bahagia dan sedih. }\end{array}$ & Tanda keseriusan seseorang & $\begin{array}{l}\text { Mimik wajah serius } \\
\text { menandakan anas } \\
\text { sebetulnya menjaga susana } \\
\text { emosi hati agar tetap terlihat } \\
\text { tenang didepan publik. Anas } \\
\text { sangat pandai } \\
\text { menyembunyikan } \\
\text { perasaannya dimana emosi } \\
\text { sangat terjaga dan diatur. } \\
\text { Anas tipe orang yang } \\
\text { menyerap banyak ilmu dari } \\
\text { orang-orang di sekitarnya. } \\
\text { Dia }\end{array}$ \\
\hline $\begin{array}{l}\text { Bibir mengatup } \\
\text { Bibir merupakan satu dari } \\
\text { elemen penting ekspresi } \\
\text { wajah. Bibir yang mengatup } \\
\text { menggambarkan fungsi } \\
\text { kontrol tubuh atas }\end{array}$ & Enggan bicara banyak. & $\begin{array}{l}\text { Bibir yang mengatup } \\
\text { menandakan Anas sangat } \\
\text { hati-hati dalam berbicara } \\
\text { yang didahului proses } \\
\text { berpikir yang cermat. }\end{array}$ \\
\hline $\begin{array}{l}\text { Kacamata } \\
\text { Merupakan artefak atau } \\
\text { benda-benda yang melekat } \\
\text { pada diri seseorang yang } \\
\text { dapat melengkapi informasi } \\
\text { tentang karakter orang } \\
\text { tersebut. }\end{array}$ & $\begin{array}{l}\text { Alat bantu melihat identitas, } \\
\text { dan sarana tampil gaya. }\end{array}$ & 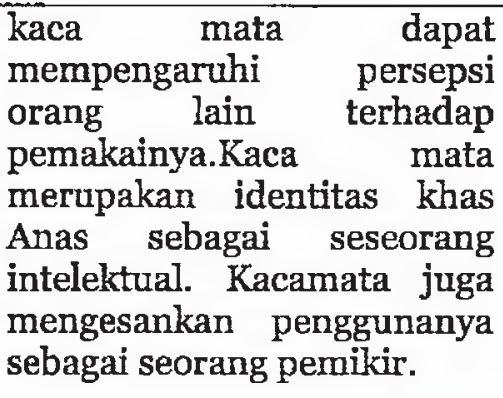 \\
\hline
\end{tabular}




\begin{tabular}{|c|c|c|}
\hline Tanda & Makna lama & Makna baru \\
\hline $\begin{array}{l}\text { Pakaian } \\
\text { Menurut Malcolm Barnard } \\
\text { (1996). fungsi pakaian } \\
\text { adalah melindungi kita dari } \\
\text { berbagai situasi dan kondisi } \\
\text { Contohnya: melindungi kita } \\
\text { dari cuaca yang buruk, } \\
\text { sengatan serangga, } \\
\text { kemungkinan cedera ketika } \\
\text { berolahraga. Fungsi paling } \\
\text { utama adalah } \\
\text { menyembunyikan bagian- } \\
\text { bagian tertentu dari tubuh } \\
\text { katta yang tidak boleh } \\
\text { diperlihatkan kepada orang } \\
\text { lain. Fungsi pakaian di atas } \\
\text { raerupakan fungsi umum } \\
\text { dari pakaian saja }\end{array}$ & $\begin{array}{l}\text { Pakaian juga } r \text { dapat } \\
\text { mengungkapkan identitas } \\
\text { kelompok, karena di dalam } \\
\text { suatu kelompok pasti } \\
\text { terdapat pakaian khusus } \\
\text { kelompok (atribut) agar } \\
\text { masyarakat mengetahui } \\
\text { bahwa orang tersebut } \\
\text { merupakan } \\
\text { kelompok. bagian } \\
\text { Warna biru sebagai warna } \\
\text { yang dominan pada Partai } \\
\text { Demokrat seperti halnya } \\
\text { samudera yang mernbentang } \\
\text { luas sebagai terminal bagi } \\
\text { aliran dan muara dari } \\
\text { berbagi sungai yang } \\
\text { membawa segala macam } \\
\text { limbah, membaur dan } \\
\text { menyatu mnejadi jernih, } \\
\text { namun terlihat berwarna } \\
\text { kebiruan, tenang, damai. } \\
\text { Partai Demokrat tampil } \\
\text { sebagai partai politik yang } \\
\text { mampu menhimpun segera } \\
\text { warga negara Indonesia } \\
\text { untuk hidup bersama dan } \\
\text { berdampingan secara damai } \\
\text { dan saling menghormati } \\
\text { antar sesama anak bangsa } \\
\text { yang emmiliki } \\
\text { keanekaragaman suku, ras, } \\
\text { agama dan golongan. }\end{array}$ & $\begin{array}{l}\text { Jaket biru - jenis pakaian } \\
\text { yang menunjukan } \\
\text { pemakainya menjadi bagian } \\
\text { dari komunitas politik partai } \\
\text { demokrat. } \\
\text { Setelah selesai - pidato Anas } \\
\text { melepas jaket partai, yang } \\
\text { menandakan ini adalah hari } \\
\text { perpisahan dimana hari itu } \\
\text { dirinya, sudah tidak lagi } \\
\text { menjadi bagian dari partai } \\
\text { Demokrat. } \\
\text { Ketika Anas melepas Jaket } \\
\text { Partai, Anas melepaskan } \\
\text { segala nilai yang selama ini } \\
\text { menyatu dalam dirinya. } \\
\text { Dengan melepas simbol } \\
\text { identitas itu, Anas menjadi } \\
\text { manusia Ka } \\
\text { merdeka.Keputusannya } \\
\text { untuk tidak lagi mennjadi } \\
\text { bagian diri partai biru itu } \\
\text { semata-mata karena tekanan } \\
\text { dari pihak-pihak yang tidak } \\
\text { menginginkan dirinya } \\
\text { sebagai pemimpin partai } \\
\text { yang mempunyai kuasa } \\
\text { penuh atas kendali partai. } \\
\text { Kekecewaannya pada partai } \\
\text { juga membuktikañ baha } \\
\text { nilai-nilai demokratis } \\
\text { ternyata jauh sekali dengan } \\
\text { fakta dan peristiwa yang ia } \\
\text { alami. Dam setiap } \\
\text { pengambilan keputusan } \\
\text { ternyata restu sBY sebagai } \\
\text { patron tunggal masih sangat } \\
\text { kuat, dengan demikian } \\
\text { tradisi keterbukaan dan } \\
\text { kesamaan hak dianggapnya } \\
\text { sebagai hal yang belum dapat } \\
\text { diwujudkan. }\end{array}$ \\
\hline
\end{tabular}


Hani Yuniani, Mythology Politik Jawa dalam Pidato Anas Urbaningrum (Analisis Semiotika Roland Barthes dalam Pidato Anas Urbaningrum Terkait Kasus Korupsi Hambalang)

Tabel 2. Makna Pidato Politik Anas Urbaningrum

\begin{tabular}{|c|c|c|}
\hline Aspek & $\begin{array}{l}\text { Kata/kalimat/artefak/ } \\
\text { gerak tubuh }\end{array}$ & Măkona \\
\hline \multirow[t]{9}{*}{$\begin{array}{l}\text { Pesan } \\
\text { Linguistik }\end{array}$} & "Kekuatan yang besar' & $\begin{array}{l}\text { Kemampuan fisik yang luar biasa sehingga } \\
\text { mampu melakukan hal-hal di luar } \\
\text { kemampuan orang biasa }\end{array}$ \\
\hline & 'Faktor non huknum' & $\begin{array}{l}\text { Non berarti bukan/ tidak. Pemisahan secara } \\
\text { mutlak. Bukan faktor hukum seperti yang } \\
\text { tersebar luas di media. }\end{array}$ \\
\hline & $\begin{array}{l}\text { 'Bayi yang lahir tidak } \\
\text { diharapkan' }\end{array}$ & $\begin{array}{l}\text { Anak haram, anak yang kelahirannya terlalu } \\
\text { cepat, atau anak yang lahir bukan dari garis } \\
\text { keturunan sang raja }\end{array}$ \\
\hline & 'Halaman Pertama' & $\begin{array}{l}\text { Halaman Pertama identik dengan sebuah } \\
\text { buku. Biasanya berisi pengantar dan latar } \\
\text { belakang peristiwa }\end{array}$ \\
\hline & 'Terima Kasih' & $\begin{array}{l}\text { Ucapan yang umumnya disampaikan kepada } \\
\text { orang yang telah memberikan bantuan baik } \\
\text { jasa maupun material. }\end{array}$ \\
\hline & 'Di atas segalanya' & $\begin{array}{l}\text { Umumnya orang menggunakan kata di atas } \\
\text { untuk menggambarkan keberadaan Tuhan. } \\
\text { Pihak yang sangat berkuasa }\end{array}$ \\
\hline & 'Politik keras dan panas' & $\begin{array}{l}\text { Keras lawan kata dari lembut. Panas lawan } \\
\text { kata dari dingin dan sejuk }\end{array}$ \\
\hline & 'Bebas dan Merdeka' & $\begin{array}{l}\text { Bebas: } \\
\text { a. Lepas sama sekali, ( tidak terhalang, } \\
\text { terganggu, sehingga dapat bergerak, } \\
\text { berbicara, berbuat, dan sebagainya). } \\
\text { b. Lepas dari (kewajiban, tuntutan, } \\
\text { perasaan takut, dan sebagainya) } \\
\text { c. Tidak terikat atau terbebas dari aturan. } \\
\text { Sedangkan kata "merdeka" dapat dimaknai } \\
\text { sebagai tidak dijajah, diperintah, dan lain- } \\
\text { lain) }\end{array}$ \\
\hline & $\begin{array}{l}\text { 'Bekerja } \\
\text { kesungguhan' }\end{array}$ & $\begin{array}{l}\text { Kerja keras yaitu mengerahkan segala } \\
\text { kemampuan dan tenaga agar pekerjaan } \\
\text { dapat terselesaikan dengan baik }\end{array}$ \\
\hline \multirow[t]{4}{*}{$\begin{array}{l}\text { Pesan Ikonik } \\
\text { Terkodekan }\end{array}$} & Jaket Biru & $\begin{array}{l}\text { Jaket biru adalah simbol identitas Partai } \\
\text { Demokrat. Anas dan SBY senantiasa } \\
\text { mengenakan jaket biru ini dalam berbagai } \\
\text { kesempatan terutama event-event besar } \\
\text { partai }\end{array}$ \\
\hline & Rompi orange & $\begin{array}{l}\text { merupakan identitas personal memperjelas } \\
\text { status Anas sebagai tersangka kasus korupsi } \\
\text { yang akan ditahan di Rutan KPK. }\end{array}$ \\
\hline & Tangan mengepal & 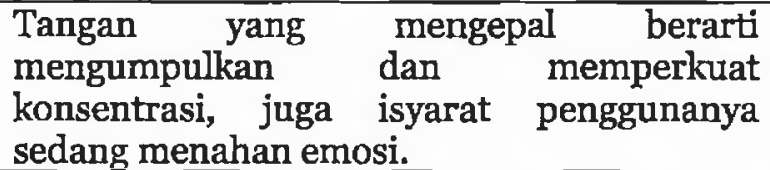 \\
\hline & $\begin{array}{l}\text { Senyum yang ditarik sedikit } \\
\text { ke arah kiri }\end{array}$ & $\begin{array}{l}\text { Senyum yang menyiratkan sindiran, } \\
\text { mencemooh. }\end{array}$ \\
\hline
\end{tabular}


Tabel 3. Pesan Linguistik Anas Urbaningrum

\section{PART 8}

\section{OBJEK}

"Saya sadar betul bahwa politik kadang-kadang keras dan kasar. Dalam politik, Tidak sulit menemukan intrik, fitnah dan serangan-serangan itu. saya sadari sejak awal dan karena tahu saya tahu persis konsekuensinya."

\begin{tabular}{|c|c|}
\hline No & Penanda \\
\hline 1 & $\begin{array}{l}\text { Politik keras dan kasar: } \\
\text { Kasar dapat berarti tidak rata, tidak } \\
\text { seimbang, kurang kontrol sendiri, tidak } \\
\text { selaras, jelek, kotor. Dalam konteks ini, } \\
\text { penuh dengan problema dalam } \\
\text { persaingan merebut kekuasaan. } \\
\text { Dorongan agar Anas mundur sudah lama } \\
\text { disuarakan berbagai pilhak setelah } \\
\text { terseret dalam kasus dugaan korupsi. } \\
\text { Politisi Demokrat Ruhut Sitompul } \\
\text { konsisten dan gamblang mendesak Anas } \\
\text { mundur. Ketidakjelasan status Anas } \\
\text { ketika itu dinilai menyandera partai. } \\
\text { Akibatnya, partai terancam "karam" di } \\
\text { Pemilu 2o14 setelah elektabilitas partai } \\
\text { terus merosot. }\end{array}$ \\
\hline 2 , & $\begin{array}{l}\text { Resiko berpolitik adalah akibat yang } \\
\text { kurang menyenangkan dapat dijelaskan } \\
\text { sebagai sesuatu yang merugikan, } \\
\text { membahayakan dari suatu perbuatan } \\
\text { atau tindakan dalam berpolitik Difitnah } \\
\text { dan diserang merupakan resiko } \\
\text { berpolitik. }\end{array}$ \\
\hline
\end{tabular}

Kalimat ini mengungkakan kekecewaan

Anas akan cara-cara inkonstitusional yang

dilakukan Kawanbin dalam mendepak

dirinya. Dengan kata lain ia merasa

dikriminalisasi. Jika slogan $P D$ bersih-

bersih partai bukan basa-basi, maka

seharusnya banyak kader yang harus

diproses kasus hukumnya, namun, sampai

saat ini, masih banyak Ketua DPC yang

bermasalah tapi tak tesentuh hukum sama

sekali. Anas merasa diperlakukan tidak adil.

Sikap kasar dinilai rendah oleh orang Jawa , sebagai kurang berbudaya, kurang konrol diri dan kelemahan batin,. Bersikap kasar dan emosional selalu memperlemah kedudukan seorang atasan.

Pernyataan Anas pada awal mula kasus Hambalang ditanyakan padanya dijawa dengan penuh keyakinan, saya sama sekali tidak terkait kasus Hambalang. Namun, setiap hari pemberitaan Anas (yang disimplifikasi sebagai fitnah) menjadi headline terutama di TVOne dan MetroTV. Anas terus dijaga agar tetap berada pada "zona serangan" yang akan menguntungkan lawan-lawan politiknya.

3. konsekuensi-konsekuensinya

1. Akibat (dari suatu perbuatan, pendirian, dsb)

2. Persesuaian dengan yang dahulu

(diulang sebanyak dua kali), frasa ini bermakna bahwa jika seseorang telah berani memasuki dunia politik, resikonya pasti ada pihak yang pro dan kontra terhadap pemikiran-pemikiran politik yang disampaikan. Pasti akan ada orang yang menyukai tetapi banyak pula yang akan tidak menyukainya. Pihak yang tidak suka akan melakukan berbagai cara agar lawan dapat kalah, takluk dan lenyap dari panggung politik sehingga diri sendiri bisa selamat, bahkan dapat mengambil keuntungan dengan menjabat posisi penting dalam partai. 
Hani Yuniani, Mythology Politik Jawa dalam Pidato Anas Urbaningrum (Analisis Semiotika Roland Barthes dalam Pidato Anas Urbaningrum Terkait Kasus Korupsi Hambalang)

Tabel 4. Proses Semiosis Pidato Politik Anas Urbaningrum

\begin{tabular}{|c|c|c|}
\hline Tanda & Makna Lama & Makna Baru \\
\hline 'Kekuatan yang besar & $\begin{array}{l}\text { Kemampuan fisik - yang } \\
\text { luar biasa sehingga } \\
\text { mampu melakukan hal- } \\
\text { hal di luar kemampuan } \\
\text { orang biasa }\end{array}$ & $\begin{array}{l}\text { 'Kekuatan' mengalami perubahan } \\
\text { makna menjadi kekuasaan. Di } \\
\text { republik ini, hanya seorang presiden } \\
\text { yang memiliki kekuasaan penuh di } \\
\text { lembaga eksekutif. Presiden melalui } \\
\text { perangkat negara mampu menekan } \\
\text { dan mengintervensi hukum. Presiden } \\
\text { dapat memberikan instruksi siapa } \\
\text { yang harus diperiksa, ditahan dan } \\
\text { dalam waktu yang bersamaan pula } \\
\text { seorang presiden dapat melindungi } \\
\text { seorang koruptor. }\end{array}$ \\
\hline 'Faktor non hukum' & $\begin{array}{l}\text { Non berarti bukan/ tidak. } \\
\text { Pemisahan secara mutlak. } \\
\text { Bukan faktor hukum } \\
\text { seperti yang tersebar luas } \\
\text { di media. }\end{array}$ & $\begin{array}{l}\text { Non-hukum yang dimaksud Anas jelas } \\
\text { faktor politis. Hampir dalam setiap } \\
\text { kesempatan, ia selalu menolak } \\
\text { (menghindar) dari pertanyaan } \\
\text { wartawan yang menanyakan perihal } \\
\text { detail kasus Hambalang, ia selalu } \\
\text { melempar pertandaan yang muaranya } \\
\text { mengarah pada kubu SBY. Tak seperti } \\
\text { rekannya Andi Mallarangeng yang tak } \\
\text { pernah ancam-mengancam, Anas } \\
\text { berusaha melawan dengan sekuat } \\
\text { tenaga. Yang ia miliki memang } \\
\text { retorika politik yang mumpuni } \\
\text { sehingga masyarakat pun dapat } \\
\text { tersihir dengan kata-katanya, } \\
\text { sehingga stigma negatifyang ia terima } \\
\text { dapat ditembakkan kembali kepada } \\
\text { Kawanbin PD. Non hukum berarti } \\
\text { kasus suap P3SON sama sekali tidak } \\
\text { ada kitannya dengan dirinya. } \\
\text { Semuanya fitnah dan rekayasa maha } \\
\text { besar. }\end{array}$ \\
\hline $\begin{array}{l}\text { 'Bayi yang lahir tidak } \\
\text { diharapkan' }\end{array}$ & $\begin{array}{l}\text { Anak haram, anak yang } \\
\text { kelahirannya terlalu cepat, } \\
\text { atau anak yang lahir } \\
\text { bukan dari } \\
\text { keturunan sang raja }\end{array}$ & $\begin{array}{l}\text { Kalimat bayi yang tidak diharapkan } \\
\text { lahir mengalami perubahan makna } \\
\text { dalam konteks kehidupan Anas di } \\
\text { partai politik, dari awal yang menjabat } \\
\text { bidang politik partai, kemudian } \\
\text { memberanikan diri maju menjadi } \\
\text { calon Ketua Umum walau tanpa restu } \\
\text { SBY. SBY yang marah karena } \\
\text { 'settingannya' tidak berhasil, } \\
\text { membombardir Anas dengan berbagai } \\
\text { cara dan yang paling ampuh yang } \\
\text { paling kuat melalui kasus hukum. }\end{array}$ \\
\hline 'Halaman Pertama' & $\begin{array}{l}\text { Halaman Pertama identik } \\
\text { dengan sebuah buku. } \\
\text { Biasanya berisi pengantar }\end{array}$ & $\begin{array}{l}\text { Anas menganalogikan dirinya seperti } \\
\text { sebuah buku. Ia meminta agar } \\
\text { masyarakat dapat 'membaca' dirinya. }\end{array}$ \\
\hline
\end{tabular}




\begin{tabular}{|c|c|c|}
\hline Tanda & Makna Lama & Makna Baru \\
\hline & $\begin{array}{l}\text { dan latar belakang } \\
\text { peristiwa }\end{array}$ & $\begin{array}{l}\text { Membaca semua peristiwa tentang } \\
\text { dirinya. Anas berusaha menarik } \\
\text { simpati masyarakat. }\end{array}$ \\
\hline $\begin{array}{l}\text { Flalaman selanjutnya } \\
\text { lebih bermakna }\end{array}$ & $\begin{array}{l}\text { Jika diibaratkan sebuah } \\
\text { buku cerita, semakin } \\
\text { memasuki halaman } \\
\text { selanjutnya semakin seru } \\
\text { dan menegangkan }\end{array}$ & $\begin{array}{l}\text { Halaman selanjutnya memiliki makna } \\
\text { konotasi sebagai ancaman. Sebuah } \\
\text { warning bagi pihak-pihak yang } \\
\text { berseteru dengannya. Halaman buku } \\
\text { yang Anas janjikan ia harap } \\
\text { menimbulkan rasa keingintahuan } \\
\text { yang tinggi dai masyarakat, syukur- } \\
\text { syukur mendapat dukungan sebagai } \\
\text { wistle blower atau justice } \\
\text { collaborator. Ia juga berharap bisa } \\
\text { menjadi simbol perlawanan penguasa } \\
\text { zalim. }\end{array}$ \\
\hline 'Terima Kasih' & $\begin{array}{l}\text { Ucapan yang umumnya } \\
\text { disampaikan kepada orang } \\
\text { yang telah memberikan } \\
\text { bantuan baik jasa maupun } \\
\text { material. }\end{array}$ & $\begin{array}{l}\text { Makna terima kasih megalami } \\
\text { perubahan menjadi sindiran yang } \\
\text { tajam kepada penyidik KPK SBY. } \\
\text { Terima kasih karena ditahan, terima } \\
\text { kasih karena harus mengahdapi } \\
\text { proses hukum yang berbelit-belit, } \\
\text { terima kasih karena pernah } \\
\text { membesarkan dirinya di karir } \\
\text { politiknya sampai menjadi orang yang } \\
\text { sangat terkenal dengan tuduhan } \\
\text { koruptor. }\end{array}$ \\
\hline 'Di atas segalanya' & $\begin{array}{l}\text { Umumnya orang } \\
\text { menggunakan kata di atas } \\
\text { untuk menggambarkan } \\
\text { keberadaan Tuhan. Pihak } \\
\text { yang sangat berkuasa }\end{array}$ & $\begin{array}{l}\text { Kata 'diatas' mengalami perubahan } \\
\text { makna menjadi 'sutradara', orang } \\
\text { yang memesan kasus, orang yang } \\
\text { mendalangi peristiwa yang sangat } \\
\text { gaduh sehingga menjadi isu nasional }\end{array}$ \\
\hline $\begin{array}{l}\text { 'Politik keras dan } \\
\text { panas' }\end{array}$ & $\begin{array}{l}\text { Keras lawan kata dari } \\
\text { lembut. Panas lawan kata } \\
\text { dari dingin dan sejuk }\end{array}$ & $\begin{array}{l}\text { Kata 'keras' dan 'panas' yang } \\
\text { disandingkan dengan kata politik } \\
\text { menguatkan anggapan umum } \\
\text { masyarakat bahwa politik selamanya } \\
\text { tidak akan pernah santun dan damai. } \\
\text { Slogan Partai Demokrat yang bersih } \\
\text { dan santun menjadi luntur. Jika } \\
\text { sudah masuk dalam dunia politik, } \\
\text { maka harus siap dengan segala intrik, } \\
\text { fitnah dan serangan. Dinamika politik } \\
\text { hanya bisa dinikmati bagi orang yang } \\
\text { bermental 'petarung sejati'. }\end{array}$ \\
\hline 'Bebas dan Merdeka' & $\begin{array}{l}\text { Bebas : } \\
\text { a. Lepas sama sekali, } \\
\text { ( tidak terhalang, } \\
\text { terganggu, sehingga dapat } \\
\text { bergerak, berbicara, } \\
\text { berbuat, dan sebagainya). } \\
\text { b. Lepas dari } \\
\text { (kewajiban, tuntutan, } \\
\text { perasaan takut, dan } \\
\text { sebagainya) } \\
\text { c. Tidak terikat atau }\end{array}$ & $\begin{array}{l}\text { Kata bebas sangat kontradiksi dengan } \\
\text { statusnya sebagai tersangka. Ia } \\
\text { menggunakan logika terbalik. Jika } \\
\text { seorang dinyatakan tersangka, jelas } \\
\text { secara yuridis ia akan kehilangan hak- } \\
\text { haknya, ia akan terbelenggu di dalam } \\
\text { penjara, ia tak mempunyai kebebasan } \\
\text { beraktivitas seperti warga masyarakat } \\
\text { lainnya, tetapi dengan memilih diksi } \\
\text { bebas dan merdeka ini, ia ngin } \\
\text { mengungkapkan bahwa selama ia }\end{array}$ \\
\hline
\end{tabular}


Hani Yuniani, Mythology Politik Jawa dalam Pidato Anas Urbaningrum (Analisis Semiotika Roland Barthes dalam Pidato Anas Urbaningrum Terkait Kasus Korupsi Hambalang)

\begin{tabular}{|c|c|c|}
\hline Tanda & Makna Lama & Makna Baru \\
\hline 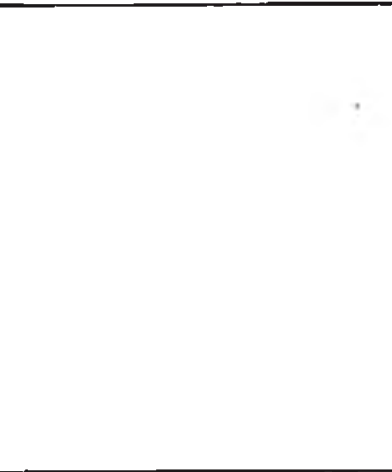 & $\begin{array}{l}\text { terbebas dari aturan. } \\
\text { Sedangkan kata } \\
\text { "merdeka" dapat dimaknai } \\
\text { sebagai tidak dijajah, } \\
\text { diperintah, dan lain-lain) }\end{array}$ & $\begin{array}{l}\text { berada di internal partai, terutama } \\
\text { sejak terpilih menjadi Ketua Umum, } \\
\text { justru ia merasa tidak bebas, ia kerap } \\
\text { diikuti oleh intelijen utusan SBY. Anas } \\
\text { harus menjaga loyalitasnya terhadap } \\
\text { Ketua Dewan Pembina. Anas pun } \\
\text { menjaga jarak dengan orang-orang } \\
\text { yang tidak disukai SBY. Dia lebih } \\
\text { tertutup dan menutup rapat } \\
\text { komunikasi dengan sahabatnya di } \\
\text { HMI. }\end{array}$ \\
\hline $\begin{array}{l}\text { 'bekerja dengan } \\
\text { kesungguhan' }\end{array}$ & $\begin{array}{lr}\text { Kerja keras } & \text { yaitu } \\
\text { mengerahkan } & \text { segala } \\
\text { kemampuan dan } & \text { tenaga } \\
\text { agar pekerjaan dapat } \\
\text { terselesaikan dengan baik }\end{array}$ & $\begin{array}{l}\text { Anas bekerja membangun dan } \\
\text { membesarkan partai, ia menjaga } \\
\text { soliditas ke DPD dan DPC di } 33 \\
\text { propinsi. Ia cukup dekat dengan } \\
\text { kader-kader di daerah. Ia menegaskan } \\
\text { bahwa ia benar-benar bekerja, bukan } \\
\text { menjilat dan membisik-bisiki SBY } \\
\text { sehingga cepat naik jabatan. Jika ia } \\
\text { memang manusia serakah, ia pasti } \\
\text { akan membawa gerbong HMI nya } \\
\text { untuk menduduiki jabatan strategis di } \\
\text { partai, tapi kenyataanya tidak, ia } \\
\text { membagi kekuasaan bahkan ia } \\
\text { melepas jabatannya sebagai Ketua } \\
\text { fraksi Demokrat di DPR. }\end{array}$ \\
\hline $\begin{array}{l}\text { Hadiah Tahun Baru } \\
2014\end{array}$ & $\begin{array}{l}\text { Hadiah : pemberian ; } \\
\text { tanda mata ; bingkisan. } \\
\text { Biasanya berupa barang, } \\
\text { uang atau fasilitas } \\
\text { tertentu. }\end{array}$ & $\begin{array}{l}\text { Makna "hadiah" menjadi sindiran } \\
\text { yang cukup sadis yang dikatakan } \\
\text { Anas, ia coba memenangkan opini } \\
\text { publik dengan mengatakan SBY lah } \\
\text { yang menginginkan penahanannya. } \\
\text { SBY lah yang sangat berkepentingan. } \\
\text { Rencana SBY berjalan mulus dan } \\
\text { lancar, tentu hatinya akan senang } \\
\text { menerima hadiah karena Anas } \\
\text { berhasil disingkirkan dari partai dan } \\
\text { berhasil dijebloskan ke dalam sel } \\
\text { tahanan. Anas mengesankan SBY } \\
\text { akan tertawa dan bahagia dengan } \\
\text { keadaan Anas ini. }\end{array}$ \\
\hline $\begin{array}{l}\text { Kebenaran } \\
\text { keadilan } \\
\text { menang }\end{array}$ & $\begin{array}{l}\text { Sesuatu yang sungguh- } \\
\text { sungguh benar ada. } \\
\text { Keadilan dapat diartikan } \\
\text { sama berat, tidak berat } \\
\text { sebelah, tidak memihak. }\end{array}$ & $\begin{array}{l}\text { Makna kebenaran menjadi sempit } \\
\text { karena klaim Anas pada kalimat ini. } \\
\text { Kebenaran yang sebelumnya } \\
\text { bermakna sesuatu yang sakral dan } \\
\text { suci menjadi ambigu karena publik } \\
\text { dihadapkan pada kebenaran versi } \\
\text { Anas. Pernyataan Anas mencari } \\
\text { keadilan membuat publik bertanya } \\
\text { masih adakah lembaga hukum yang } \\
\text { dapat dipercaya, bahkan KPK pun } \\
\text { ternyata rawan dipolitisasi. }\end{array}$ \\
\hline
\end{tabular}


5. Kesimpulan

1. Penanda dan petanda yang muncul dalam pidato Anas Urbaningum yaitu:

- 'Kekuatan yang besar ' merupakan penanda yang memiliki referen (rujukan/petanda) yaitu kekuasaan SBY sebagai kepala negara, presiden, Dewan Pembina Partai sekaligus Ketua Majlis tinggi partai yang memiliki pengaruh dan dominasi yang kuat.

- 'Faktor non hukum' merupakan petanda yang merujuk pada faktor politis internal Partai Demokrat.

- 'Bayi yang tidak diharapkan lahir' merupakan penanda yang merujuk pada kemunculan Anas sebagai pemenang kongres Partai Demokrat yang tidak diharapkan oleh "kubu Cikeas".

- 'Politik keras dan panas' - merupakan penanda yang merujuk pada intrik dan fitnah yang kejam yang ditujukan pada Anas sematamata untuk menurunkan Anas dari kursi Ketua Umum Partai Demokrat.

2. Mitos yang dimunculkan Anas dalam pidatonya terkait dengan beberapa pihak yang masuk dalam lingkaan pertandaan ini, yaitu :

\section{a. Mitologi Politik 'Alus'}

Antitesa dari politik santun yang menjadi simbol SBY berwujud pada Úngkapan Anas dalam kalimat politik keras dan kasar. Alus (halus) yang menjadi falsafah hidup orang Jawa ternyata lebih menyakitkan karena ada operasi-operasi yang berjalan begitu sistematis dalam upaya kudeta atas Anas dari kursi Ketua Umum Partai Demokrat. Di balik kesantunan dan kelembutan yang sering didengungkan para kader partai, justru terjadi praktik perebutan kekuasaan melalui serangkaian fitnah dan bisikan para sengkuni di sekitar SBY. Analogi-analogi dan sindiran dari Anas kepada SBY merupakan cara orang njawani mengekspresikan kemarahan dan kekecewaannya.

\section{b. Mitologi Patrimonial}

Budaya daerah Jawa yang bersifat kratonik sangat kentara dalam tubuh partai. Kader-kader yang dianggap "tidak loyal" kepada SBY, akan segera langsung dikeluarkan, apalagi jika tercium dekat dengan Anas Urbaningrum. Budaya kratonik semacam ini, sering dianggap'anti kritik' dan ABS (asal Bapak Senang) dan jilatisme. Implementasi budaya Jawa yang kratonik itu dan terlalu hirarkis, menghendaki bawahan harus selalu patuh. Oleh karenanya, tradisi politik modern yang diinginkan Anas sulit terwujud jika partai dikelola dengan amarah dan benci. Anas dianggap tidak loyal dan harus 'dibuang' dari partai.

\section{c. Mitologi Watak Nrima dan Rasa Rumangsa.}

Sosok Anas di televisi menjadi menarik manakala melihat politisi Jawa mengalami kezaliman penguasa. Nrima dalam pengertian falsafah hidup Jawa bukan berarti mandeg, tanpa upaya gigih. Nrima hanya sandaran psikologis. Namun, di balik itu, orang Jawa selalu percaya ada banyak jalan menuju mencari rejeki (kebebasan dari kasus hukum dalam konteks Anas). Melalui nrima dan usaha, maka keberutungan akan datang.

\section{Saran}

Ambiguitas pada beberapa kata dan kalimat yang sengaja dilempar Anas ke 
publik merupakan strategi komunkasi polititisi yang cukup ampuh sehingga menimbulkan wacana dan membentuk opini publik yang sedikit lebih objektif ketimbang opini media massa yang cenderung "memancing di air keruh" agar mendapat pundi-pundi rupiah. Bagi kalangan akademisi maupun awam yng tertarik dengan dunia pertandaan, analisis terhadap berbagai tipe retorika politisi menarik untuk dicermati mengingat terjadinya pergantian kepemimpinan SBY kepada presiden terpilih akan memunculkan politisi baru dengan berbagai macam gaya komunikasi yang tentunya mempunyai tujuan tertentu. Pemikiran kritis dan skeptis sangat diperlukan agar khalayak penonton tak hanya menerima pesan politisi tetapi dapat cermat mengenali motif dan tujuan komuniaksinya.

\section{Daftar Pustaka}

Al Barbassy, Ma'mun Murod, Anas Tumbal Cikeas, 2013, Pt. Gramedia Pustaka Utama

Barthes, Roland, 2012, Eleemen-elemen Semiologi, Yogyakarta, Jalasutra.

Bungin, Burhan, 2012, Metode Penelitian Kualitatif, Edisi Kedua, Kencana Predana Media Grup.

Danesi, Michael, 2008, Pesan, Tanda, dan Makna, Jakarta, Jalasutra

Denzin, Norman and Lincoln, 2009, Handbook of Qualitative Research, Jakarta, Pustaka Pelajar

Endraswara, Suwardi, 2013, Falsafah hidup Jawa, Yogyakarta, Cakrawala.

Fiske, John, 2002, Introduction toCcommunication Studies, New York,Taylor and Francis Library

Fiske, John Pengantar Ilmu komunikasi, 2012, Jakarta, rajawali Pers
Griffin, Em, A First Look at Communicaton Theory, 2012, USA, Mc Graw Hill

Haryanto, Sindung, 2013, Dunia Simbol Orang Jawa, IKAPI, Yogyakarta

Sobur, Alex, 2004, Semiotika komunikasi, Bandung, PT. Remaja Rosdakarya

Suseno, Frans Magnis, 1988, etika Jawa, Sebuah Ánalisa Falsafi tentang kebijaksanan Hidup Jawa, Jakarta, PT. Gramedia

www.metrotvnews.com/videoprogram/vi deos/.../Anas.../Primetime\%20New $s$ diunduh tanggal $15 \mathrm{Mei} 2014$

http://news.metrotvnews.com/read/2014 /05/13/241418/anas-bantah-semuatuduhan-nazaruddin

http://www.herdi.web.id/jejak-budayakorupsi-di-indonesia/ 